\title{
Lichen sclerosus and data science: using an age, site and gender specific disease to define correlation and causality
}

\author{
Colleen M. Reisz" and Rima Chakraborty² \\ *Correspondence: cmrderm@aol.com

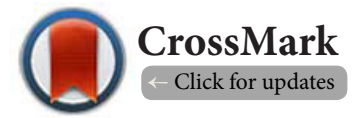

'Department of Medicine, University of Missouri-Kansas City, USA.

${ }^{2}$ Department of Medicine, University of Minnesota, Minneapolis, Minnesota, USA.

\begin{abstract}
Introduction: Lichen sclerosus (LS) is a site, gender and age specific disease that affects the vulvar region of menopausal women. The menopausal transition is characterized by physiologic changes that impact basic processes, such as weight, sleep and drug clearance. Our current pharmacopeia includes drugs that target basic metabolic processes such as cholesterol, sex steroidogenesis and the gut microbiome. Introduction of drugs engages complex pathways that govern bile salt metabolism and the provision of sex steroid substrate. We hypothesized that lichen sclerosus in the vulva may represent an off target effect of pharmaceutical alteration of sex steroid substrate in some women. We compared biometric and drug data in women with lichen sclerosus with an age matched control group without disease.

Methods: 43 women with lichen sclerosus underwent chart review to determine BMI, Fitzpatrick level, and pharmaceutical burden. This data was compared to 106 randomly selected age matched controls. Logistic regression was adjusted for age, BMI and Fitzpatrick photo typing. The statistical software was R version 3.0.1. Cases were defined as those with diagnosis claims for lichen sclerosus and were obtained from electronic records in a single private practice.

Results: Proton pump inhibitors were noted in 12/43 women (28\%) cases and 15/106 (14\%) controls: p=0.048, (confidence interval $\mathrm{CI}=-0.01$ to 0.287 ), adjusted p value 0.33 ; Hormone therapy $5 / 43$ cases (12\%), 26/106 (25\%) controls: p value 0.078 , $(\mathrm{CI}=-0.25$ to 0.002$)$, adjusted p value 0.02 . Antihypertensive medications $17 / 43$ $(40 \%)$ cases, $29 / 106(27 \%)$ controls, p value $0.14,(\mathrm{CI}=-0.047$ to 0.29$)$, adjusted $\mathrm{p}$ value 0.8 . Statins $16 / 43$ cases (37\%), 28/106 controls (26\%); $\mathrm{p}=0.19,(\mathrm{CI}=-0.05$ to 0.27$)$, adjusted $\mathrm{p}$ value 0.89 . Average age among cases was 63, average age in the control group was 61. Average BMI was 27.5 in the case group, 23.6 in the control group. Logistic regression analysis was adjusted for age, BMI and Fitzpatrick phototyping.

Conclusions: Borderline statistical significance was seen with proton pump inhibitors and hormone replacement therapy (HRT). The significance seen with proton pump inhibitors went away with adjustment for Fitzpatrick, age and BMI. The significance seen with HRT withstood adjustment, with the control group featuring more women on hormone replacement therapy than the case group.
\end{abstract}

Keywords: Fitzpatrick phototyping, lichen sclerosus, polypharmacy, drug metabolism

\section{Case presentation}

Menopause is characterized by physiologic changes that alter sleep, salt and water metabolism, insulin resistance and drug metabolism $[\mathbf{1}, \mathbf{2}]$. Drug metabolism is a complex, overlapping and competitive process that utilizes key components of cholesterol and bile metabolism [3-7]. The transport mechanisms for endogenous steroids also function in the delivery and elimination of HMG-CoA reductase inhibitors (statins), angiotensin receptor II antagonists and cardiac glycosides [8,9]. We hypothesized that lichen sclerosus may relate to competition in steroid and drug transport mechanisms at a time of physiologic change.

7 of the 43 women in this case series suspected that a recent drug change caused the problem; 3 with change in hormones, 3 with introduction of a beta blocker and 1 with introduction of 
thyroid replacement. This number is probably low, as approximately half of these patients were seen years after their initial diagnosis and could not remember the sequence of events. Many underwent months and years of treatment for other vulvar conditions, such as chronic yeast infections, before the characteristic features of lichen sclerosus emerged (Figures 1-4).

$86 \%$ of the patients were on at least one drug, with $58 \%$ on more than one drug. Hypertension was the most treated comorbid state with over half of this group on a beta blocker. $37 \%$ were on $\mathrm{HMGCoA}$ reductase inhibitors and $33 \%$ were on a drug (s) that targets the gut. Three women were extreme athletes with chronic amenorrhea. $79 \%$ were very fair, Fitzpatrick phototyping classification 1 or $2.60 \%$ had a $\mathrm{BMI}>25$.

All patients were counseled about the effect of diet and exercise on the need for prescription drugs. Patients with

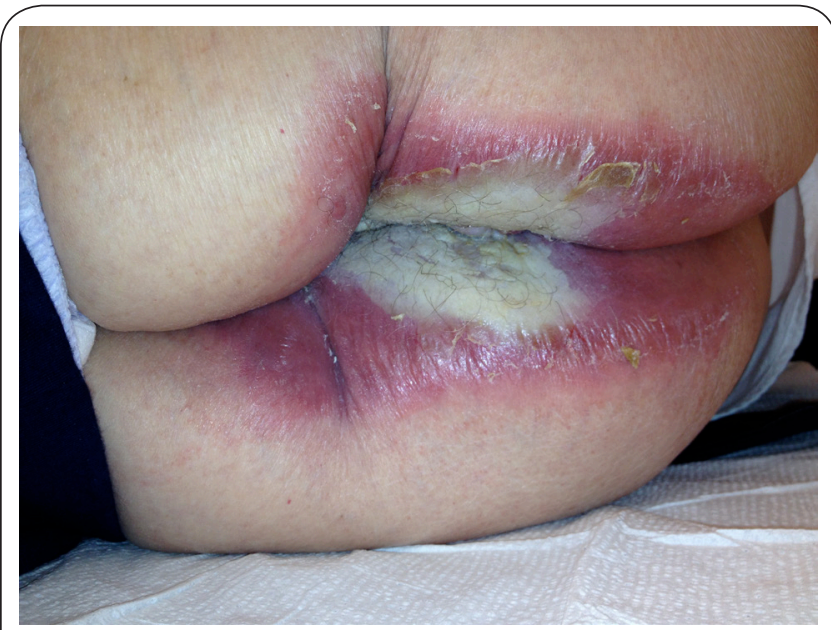

Figure 1. Drug eruption: 89 year old with polypharmacy and two year history of painful dermatitis superimposed on lichen sclerosus.

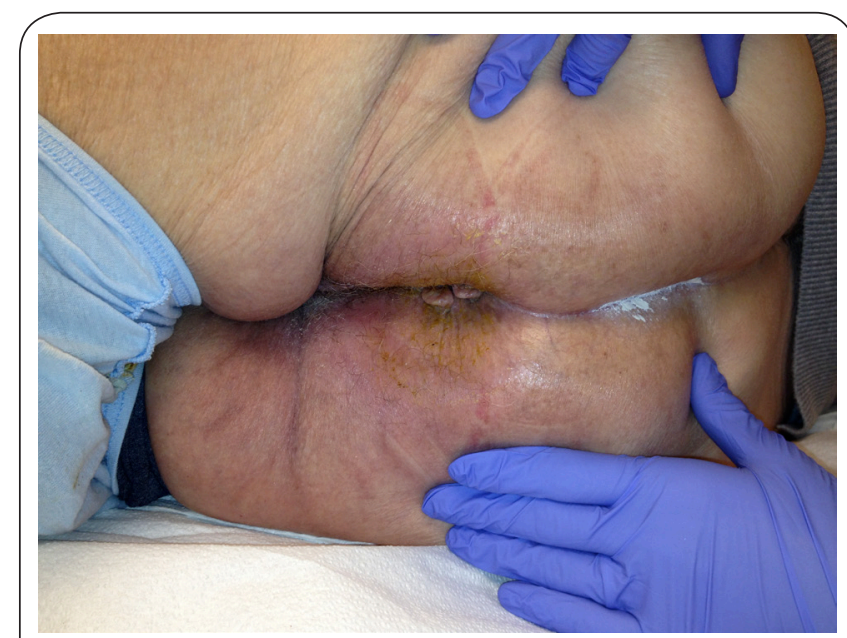

Figure 2. Drug eruption: 89 year old 4 weeks after cardiologist guided cessation of amiodarone, amlodipine and omeprazole.

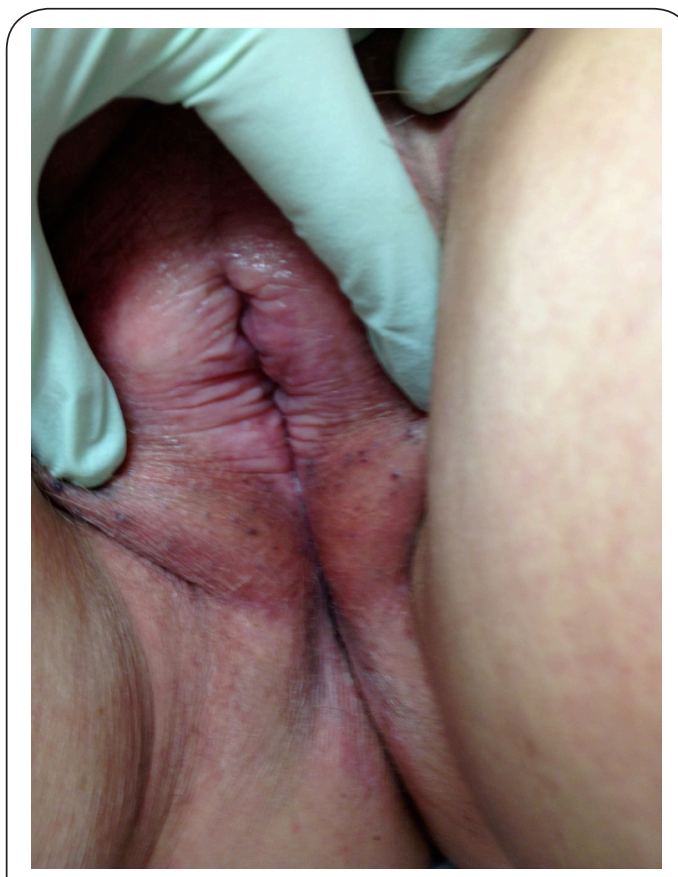

Figure 3. Lichen Sclerosus: 70 year old obese female presenting with lichen sclerosus after weaning Premarin.

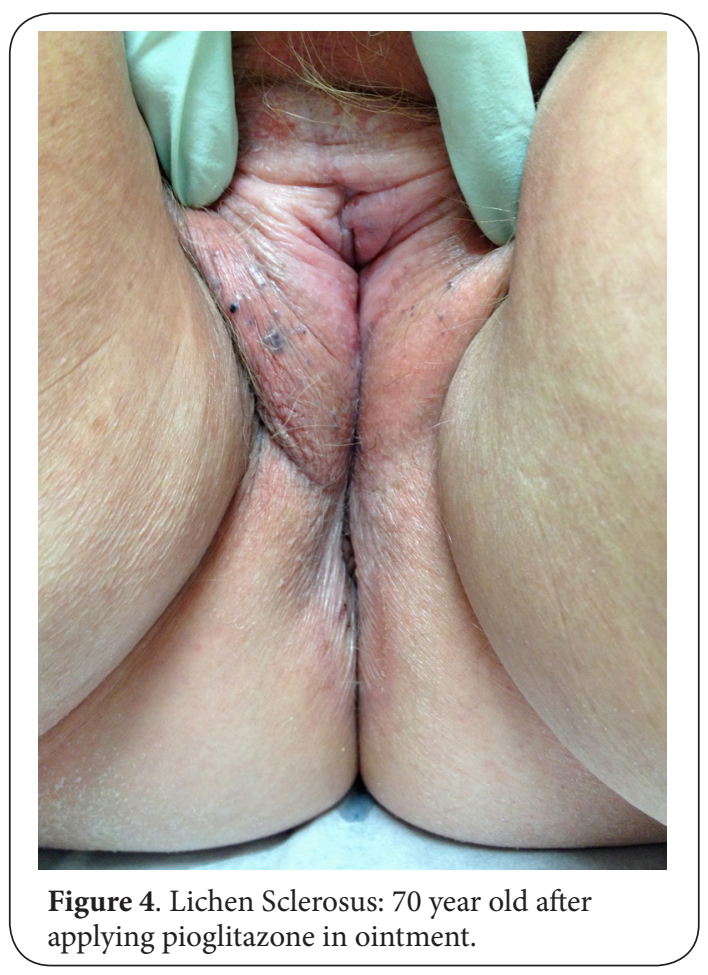

high $\mathrm{BMI}$ and those with a history of large for gestational age babies (LGA) were offered low dose metformin. Patients with severe disease resistant to clobetasol were given topical pioglitazone $30 \mathrm{mg} / \mathrm{loz}$ of petrolatum [10] (Tables 1 and 2). 
Table 1. Lichen Sclerosus: drug and biometric data in $\mathbf{4 3}$ women.

\begin{tabular}{lll}
\hline Lichen sclerosus & No=43 & \% \\
\hline Age over 50 & $41 / 43$ & $95 \%$ \\
Fitzpatrick phototyping 1-2* & $34 / 43$ & $79 \%$ \\
BMI $>25$ & $26 / 43$ & $60 \%$ \\
Beta blockers & $10 / 43$ & $23 \%$ \\
All antihypertensives & $23 / 43$ & $53 \%$ \\
statins & $17 / 43$ & $14 \%$ \\
SSRI's & $2 / 43$ & $5 \%$ \\
PPI & $14 / 43$ & $33 \%$ \\
SERM & $2 / 43$ & $5 \%$ \\
More than one drug & $25 / 43$ & $58 \%$ \\
No drug at onset & $6 / 43$ & $14 \%$ \\
Onset at time of drug change & $7 / 43$ & $16 \%$ \\
\hline
\end{tabular}

SSRI: Serotonin reuptake inhibitor; PPI: Proton pump inhibitors; SERM: Selective estrogen receptor modulator *included as a potential biomarker of genetic variation in aromatase; ${ }^{* *}$ These womenwere seen early in the course of their disease and felt the lichen sclerosus was related to introduction or withdrawal of a drug.

Table 2. Lichen Sclerosus: suggested treatment algorithm for women presenting at midlife.

$\begin{aligned} \text { LSA } \rightarrow & \text { Drug } \rightarrow \rightarrow \rightarrow \text { drug reduction } \rightarrow \rightarrow \rightarrow \text { topical pioglitazone } \\ & \begin{array}{l}\text { No drug } \rightarrow \rightarrow \rightarrow \text { BMI }>25, \text { LGA, GDM } \rightarrow \rightarrow \rightarrow \text { metformin } \rightarrow \rightarrow \\ \text { topical pioglitazone }\end{array}\end{aligned}$

BMI: Body mass index; LGA: Large gestational age;

GDM: Gestational diabetes

\section{Discussion}

The nuclear receptors that control cholesterol and bile metabolism have important functions in sex steroid substrate provision and drug clearance [11]. Older views of drug meta-bolism focused on the p450 system and fall short in predicting the variability in drug response seen in patients on multiple medications [12]. New information on transporter mechanisms, which have substrate and end organ specificity, has improved our understanding of inter-organ variability in drug response. Menopause changes cholesterol and bile metabolism and drugs impact key regulators of cholesterol and bile metabolism $[13,14]$. Bile salts and the gut microbiome provide the steroid substrate precursors essential for steroidogenesis. It may be that specific drugs in combination, such as Hmg-CoA inhibitors (statins) and proton pump inhibitors, may be problematic if introduced at times of physiologic change [15]. Dual drug combinations that require functional cytochrome 3A4 and p-glycoprotein may have difficult to measure impact at menopause, because women lose a portion of intestinal 3A4 [16].

While antihypertensives, statins and proton pump inhibitors were all found more frequently in the case group, they did not meet statistical significance. After logistic regression analysis for age, BMI and Fitzpatrick phototyping, only hormone replacement therapy, seen more frequently in the control group, maintained statistical significance.

We were limited by the inability to accurately note the onset of the disease in some women. The difficulties noting onset complicate the definition of a temporal relationship between drug introduction and onset of disease. It may be that multiple requests for treatment for yeast infections may be a curatable measurement for the onset of lichen sclerosus. In some women, lichen sclerosus is asymptomatic and only recognized on physical exam.

Concurrent changes in medical care could impact the frequency of this disease. Polypharmacy accelerates around the menopausal transition. The utilization of hormone replacement therapy is more controversial. Older, sicker and heavier women often bypass well woman exams and forego discussions on hormone replacement therapy. Off target effects of statins and proton pump inhibitors, introduced in 1987 and 1990, respectively, on diabetes risk and the gut microbiome, are more recent findings.

The work-up of patients presenting with lichen sclerosus should include a complete drug history. Advances in pharmacokinetics pertaining to gender may improve prescribing habits at menopause. Treatments offered to women with lichen sclerosus may include reduction of comorbid states through non pharmaceutical methods, reduction of specific drugs and identification of harmful drug/drug combinations at menopause.

\section{Competing interests}

The authors declare that they have no competing interests.

Authors' contributions

\begin{tabular}{|l|c|c|}
\hline Authors' contributions & CMR & RC \\
\hline Research concept and design & $\checkmark$ & -- \\
\hline Collection and/or assembly of data & $\checkmark$ & $\checkmark$ \\
\hline Data analysis and interpretation & $\checkmark$ & $\checkmark$ \\
\hline Writing the article & $\checkmark$ & $\checkmark$ \\
\hline Critical revision of the article & $\checkmark$ & -- \\
\hline Final approval of article & $\checkmark$ & $\checkmark$ \\
\hline Statistical analysis & $\checkmark$ & -- \\
\hline
\end{tabular}

Publication history

Editors: Konstantinos Dafopoulos, University of Thessalia, Greece. Erich Cosmi, University of Padua, Italy.

Received: 11-Nov-2014 Final Revised: 09-Apr-2015

Accepted: 21-Apr-2015 Published: 30-Apr-2015

\section{References}

1. Murphy R. Lichen sclerosus. Dermatol Clin. 2010; 28:707-15. | Article | PubMed

2. Polotsky HN and Polotsky AJ. Metabolic implications of menopause. 
Reisz et al. Research Journal of Women's Health 2015,

http://www.hoajonline.com/journals/pdf/2054-9865-2-1.pdf

Semin Reprod Med. 2010; 28:426-34. | Article | PubMed

3. $\mathrm{Xu} \mathrm{C}, \mathrm{Li} C Y$ and Kong AN. Induction of phase I, II and III drug metabolism/transport by xenobiotics. Arch Pharm Res. 2005; 28:249-68. | Article | PubMed

4. Timsit Timsit YE and Negishi M. CAR and PXR: the xenobiotic-sensing receptors. Steroids. 2007; 72:231-46. | Article | PubMed Abstract | PubMed Full Text

5. de Aguiar Vallim TQ, Tarling EJ and Edwards PA. Pleiotropic roles of bile acids in metabolism. Cell Metab. 2013; 17:657-69. | Article | PubMed Abstract | PubMed Full Text

6. Hernandez JP, Mota LC and Baldwin WS. Activation of CAR and PXR by Dietary, Environmental and Occupational Chemicals Alters Drug Metabolism, Intermediary Metabolism, and Cell Proliferation. Curr Pharmacogenomics Person Med. 2009; 7:81-105. | Article | PubMed Abstract | PubMed Full Text

7. Marino M, di Masi A, Trezza V, Pallottini V, Polticelli F and Ascenzi P. Xenosensors CAR and PXR at work: impact on statin metabolism. Curr Drug Metab. 2011; 12:300-11. | Article | PubMed

8. Klaassen CD and Aleksunes LM. Xenobiotic, bile acid, and cholesterol transporters: function and regulation. Pharmacol Rev. 2010; 62:1-96. Article | PubMed Abstract | PubMed Full Text

9. Borst $P$ and Elferink RO. Mammalian $A B C$ transporters in health and disease. Annu Rev Biochem. 2002; 71:537-92. | Article | PubMed

10. Yki-Jarvinen $\mathrm{H}$. Thiazolidinediones. N Engl J Med. 2004; 351:1106-18. | Article | PubMed

11. Li T and Chiang JY. Bile acid signaling in metabolic disease and drug therapy. Pharmacol Rev. 2014; 66:948-83. | Article | PubMed

12. Wilkinson GR. Drug metabolism and variability among patients in drug response. N Engl J Med. 2005; 352:2211-21. | Article | PubMed

13. Calderon-Larranaga A, Gimeno-Feliu LA, Gonzalez-Rubio F, Poblador-Plou B, Lairla-San Jose M, Abad-Diez JM, Poncel-Falco A and Prados-Torres A. Polypharmacy patterns: unravelling systematic associations between prescribed medications. PLoS One. 2013; 8:e84967. | Article | PubMed Abstract | PubMed Full Text

14. Vesper BJ, Jawdi A, Altman KW, Haines GK, 3rd, Tao L and Radosevich JA. The effect of proton pump inhibitors on the human microbiota. Curr Drug Metab. 2009; 10:84-9. | Article | PubMed

15. Blume $H$, Donath F, Warnke A and Schug BS. Pharmacokinetic drug interaction profiles of proton pump inhibitors. Drug Saf. 2006; 29:76984. | Article | PubMed

16. Zhou YT, Yu LS, Zeng S, Huang YW, Xu HM and Zhou Q. Pharmacokinetic drug-drug interactions between 1,4-dihydropyridine calcium channel blockers and statins: factors determining interaction strength and relevant clinical risk management. Ther Clin Risk Manag. 2014; 10:1726. | Article | PubMed Abstract | PubMed Full Text

\section{Citation}

Reisz CM and Chakraborty R. Lichen sclerosus and data science: using an age, site and gender specific disease to define correlation and causality.

Res J of Womens Health. 2015; 2:1.

http://dx.doi.org/10.7243/2054-9865-2-1 